University of Nebraska - Lincoln

DigitalCommons@University of Nebraska - Lincoln

January 1996

\title{
TRACK STRUCTURE AND RADIATION TRANSPORT MODEL FOR SPACE RADIOBIOLOGY STUDIES
}

\author{
F. A. Cucinotta \\ NASA Langley Research Centre, Hampton, VA, francis.cucinotta@unlv.edu \\ J. W. Wilson \\ NASA Langley Research Centre, Hampton, VA \\ Robert Katz \\ University of Nebraska-Lincoln, rkatz2@unl.edu \\ W. Atwell \\ Rockwell Aerospace, Houston, TX \\ G. D. Badhwar \\ NASA Johnson Space Centre, Houston, TX \\ See next page for additional authors
}

Follow this and additional works at: https://digitalcommons.unl.edu/physicskatz

Part of the Physics Commons

Cucinotta, F. A.; Wilson, J. W.; Katz, Robert; Atwell, W.; Badhwar, G. D.; and Shavers, M. R., "TRACK STRUCTURE AND RADIATION TRANSPORT MODEL FOR SPACE RADIOBIOLOGY STUDIES" (1996). Robert Katz Publications. 67.

https://digitalcommons.unl.edu/physicskatz/67

This Article is brought to you for free and open access by the Research Papers in Physics and Astronomy at DigitalCommons@University of Nebraska - Lincoln. It has been accepted for inclusion in Robert Katz Publications by an authorized administrator of DigitalCommons@University of Nebraska - Lincoln. 


\section{Authors}

F. A. Cucinotta, J. W. Wilson, Robert Katz, W. Atwell, G. D. Badhwar, and M. R. Shavers 


\title{
TRACK STRUCTURE AND RADIATION TRANSPORT MODEL FOR SPACE RADIOBIOLOGY STUDIES
}

\author{
F. A. Cucinotta,* J. W. Wilson,* R. Katz,** W. Atwell,*** \\ G. D. Badhwar $\ddagger$ and M. R. Shavers $\ddagger$ \\ * NASA Langley Research Centre, Hampton, VA 23681-0001, U.S.A. \\ ** University of Nebraska, Lincoln, NE 68588-0111, U.S.A. \\ *** Rockwell Aerospace, Houston, TX 77058, U.S.A. \\ † NASA Johnson Space Centre, Houston, TX 77058, U.S.A. \\ $\ddagger$ Texas A \& M University, College Station, TX 77843-3133, U.S.A.
}

\begin{abstract}
Radiobiology experiments performed in space are deemed necessary for validation of risk-assessment methods. The understanding of space radiobiology experiments must combine knowledge of the space radiation environment, radiation transport, and models of biological response. The heavy ion transport code HZETRN has recently been combined with improved models of the galactic cosmic rays (GCR) and extensive comparisons made to measurements on the space shuttle with a tissue equivalent, proportional counter. HZETRN was also coupled with track-structure models of biological damage from heavy ions. Track-structure calculations using improved models of the radial dose distribution around the path of heavy ions provide a good description of ground-based experiments for inactivation cross sections. Therefore, we use these models to predict inactivation of Bacillus Subtilis spores in space. Calculations consider single-particle effects, as well as the background from low linear energy transfer ions of the GCR and trapped radiations on the radial distributions of effects measured in plastic detectors.
\end{abstract}

\section{INTRODUCTION}

1996. Published by Elsevier Science Ltd on behalf of COSPAR

Risk assessment for future manned space flight requires validation of methods of predicting the expected harmful biological effects. Ground-based facilities are necessary to develop and verify physical models for radiation transport, interaction cross sections for the transport model, and track structure effects in energy deposition. Animal and cell experiments may provide understanding of biological effects such as carcinogenesis, mutation, and damage to the central nervous system. Ground-based radiation biology experiments with monoenergetic ion beams may aid the development of models of heavy ion effects and serve as basic information to estimate space exposure of astronauts. These ground-based models are combined with dynamic space environment data and spacecraft shielding properties to provide the final prediction of risk to astronauts on space missions. The validation of these risk evaluation methods required for spaceflight also must consider the expected radiation environment to be encountered after modification by spacecraft and body shielding, and eventually of radiobiological response of test biological systems, preferably those used in the ground-based models. The outcome of the validation process would include considerations on the modification of the response due to microgravity and the physiological stresses of spaceflight. The assignment of the error in the risk estimates is required to complete the validation process for space radiation risk assessment / $1 /$.

The scientific development and validation process for space radiations will continue for many years. The emphasis of the present work will be on the spacecraft validation of both radiation transport models and models of biophysical damage. The Langley Research Center has a vigorous program in the development of laboratory and space radiation transport codes for HZE particles. The 
transport codes as developed by Wilson et al. /2-4/ are built on the premise that the required transport methods must be amendable to validation with laboratory HZE beams. Badhwar and O'Neill /5/ have developed a model of the galactic cosmic ray (GCR) environment which is included in the HZETRN code /4/ and represents a substantial improvement in the representation of the GCR environment over earlier models /6/. Recent measurements onboard the space shuttle have been made with an active tissue equivalent proportional counter (TEPC). Ongoing comparisons of dose and dose equivalent between the TEPC and transport models are being made along with comparisons between measured lineal energy $(y)$ spectrum and calculated linear energy transfer (LET) spectrum /7/. The validity of such comparisons are limited by the large width of the ion track, energy loss fluctuations in crossing the gas volume, leakage of electrons generated in the counter walls into the sensitive volume, and nuclear fragmentation effects within the device /8/. Future measurements are expected with particle telescopes, allowing for identification of particle type and energy for direct comparisons to calculated particle energy spectra.

Spaceflight radiobiology experiments have been recently reviewed by Horneck /9/and Nelson /10/. An experiment measuring the inactivation of spores of Bacillus Subtilus (B. Spores) as a function of the impact parameter from single HZE particles has been made in the Biostack experiments on Apollo 16 and 17 and on the Apollo-Soyuz Test Project (ASTP). In these experiments the spores are held in contact with a plastic detector sheet (cellulose nitrate). Etching techniques allow for identification of the inactivation versus impact parameter to an accuracy of about $\pm 0.2 \mu \mathrm{m}$. Measurements suggest that the inactivation probability extends to much larger distances than expected from ground-based measurements /11/. Cellulose nitrate has a threshold response for particle identification which prohibits identification of particles below threshold values in energy deposition. We use the action cross section model of Katz /12/ combined with models of the radiation environment and transport to predict the damage rate from the background of particles not identifiable in the Biostack experiment. More recently radiobiology experiments have been undertaken on the International Microgravity Laboratory (IML) flown on the space shuttle and it is expected that new space radiobiology data will be available in the future.

In the present report we consider the space validation process for a limited measurement of the physical fields within a spacecraft in comparison to the HZETRN code. We further consider the use of a ground-based biological model for $B$. Spores studied in heavy ion accelerators using the track structure model of Katz /12/. Finally, we try to explain inactivation effects measured in the Biostack experiments using the radiation transport and track structure model in an attempt to validate these models for spaceflight. Our ability to predict the response of such simple systems must support our confidence in predicting risks for astronauts in future space missions.

\section{GALACTIC HEAVY ION TRANSPORT MODEL}

The propagation of the GCR and their secondaries through bulk matter is described by the Boltzman equation which in the straightahead approximation is of the form $/ 2,13 /$ :

$$
\left[\frac{\partial}{\partial x}-\nu_{j} \frac{\partial}{\partial E} S(E)+\sigma_{j}(E)\right] \phi_{j}(E)=\sum_{k} \int_{0}^{\infty} f_{j k}\left(E, E^{\prime}\right) \phi_{k}\left(x, E^{\prime}\right) d E^{\prime}
$$

where $\nu_{j}$ denotes the range scaling parameter which is equal to $Z_{j}{ }^{2} / A_{j}$ where $A_{j}$ and $Z_{j}$ are the charge and mass numbers of ion $j$, respectively. In equation (1), $E$ represents energy (MeV/amu), $S(E)$ is the proton stopping power, $\sigma(E)$ is the total cross section, $\phi_{j}(x, E)$ is the differential flux spectrum, and $f_{j k}\left(E, E^{\prime}\right)$ is the differential energy cross section for redistribution of particle type and energy through elastic scattering or nuclear reactions such as fragmentation. The numerical solution to equation (1) has been developed by Wilson et al. /13/ using the method of characteristics with the production terms separated into projectile fragmentation and target fragmentation terms.

The HZETRN code uses energy dependent nuclear interaction cross sections and assumes realistic energy spectra for light mass particles $(A<4)$. For heavy ions, secondaries are assumed to be produced at the velocity of the projectile nucleus. Further details on the transport methods and data base are found in $/ 2-4 /$. 
The free space GCR energy spectrum has been calculated by Badhwar and O'Neill by fitting measured differential energy spectra from 1954-1989 to the stationary Fokker-Plank equation to estimate the diffusion coefficient or equivalently the deceleration parameter $/ 5 /$. It has been shown by Badhwar and O'Neill /5/ that this description fits the existing data to a root mean square error of about $10 \%$ nearly independent of the energy. Values for the deceleration parameter $\phi(M V)$ are obtained using the linear correlation of the derived $\phi(M V)$ and the measured Climax neutron monitor rate and the polarity of the interplanetary magnetic field. Further details of this model are given in references $/ 5,7 /$. The free space GCR spectrum are modified using the orbit averaged geomagnetic transmission functions from the CREME code /6/ including earth shadowing and then inputted into HZETRN as a boundary value for transport inside spacecraft shielding. Low LET particles from the splash albedo are calculated in $/ 7 /$ using the splash proton energy spectrum of Armstrong and Colburn /14/.

In Table 1 are comparisons of TEPC measurements and calculated dose and dose equivalent from the GCR on recent shuttle missions. For the lightly shielded payload bay and dosimeter location 2 (DLOC2) on the shuttle the agreement is generally within 15\%. In Figure 1, a comparison of calculations with the TEPC measurements for the integral LET spectrum on STS-56 is shown. We note that the measurements are for the lineal energy transfer $y$ in a $2 \mu \mathrm{m}$ right circular cylinder, while the calculations are for the unrestricted LET. The agreement between calculations and the TEPC is quite good between values of $y$ or LET of $50-200 \mathrm{keV} / \mu \mathrm{m}$.

TABLE 1 Comparison of measured and calculated doses in spaceflight

\begin{tabular}{|c|c|c|c|c|}
\hline \multicolumn{5}{|c|}{ STS-56 $\left(57^{\circ} \times 290 \mathrm{~km}\right)$} \\
\hline Location & $\begin{array}{c}\text { Dose } \\
\mu \mathrm{Gy} / \text { day }\end{array}$ & $\begin{array}{c}\text { Dose Equivalent } \\
\mu \mathrm{Sv} / \text { day }\end{array}$ & $\begin{array}{l}\text { Quality } \\
\text { Factor }\end{array}$ & Remarks \\
\hline Payload (TEPC) & 112.7 & 422.0 & 3.74 & ICRP-60 \\
\hline $\begin{array}{l}\text { GCR Model } \\
\text { Albedo } \\
\text { Total (Model) }\end{array}$ & $\begin{array}{r}94.6 \\
14.0 \\
108.6\end{array}$ & $\begin{array}{r}400.4 \\
34.0 \\
434.4\end{array}$ & $\begin{array}{l}4.27 \\
2.43 \\
4.00\end{array}$ & $\begin{array}{l}\text { ICRP-60 } \\
\text { ICRP-60 } \\
\text { ICRP-60 }\end{array}$ \\
\hline (TEPC/Model) & 1.04 & 0.97 & 0.94 & ICRP-60 \\
\hline Dloc2 (TEPC) & 138.3 & 414.0 & 2.99 & ICRP-26 \\
\hline $\begin{array}{l}\text { GCR Model } \\
\text { Albedo } \\
\text { Total (Model) }\end{array}$ & $\begin{array}{r}102.0 \\
8.0 \\
110.0\end{array}$ & $\begin{array}{r}358.0 \\
12.0 \\
370.0\end{array}$ & $\begin{array}{l}3.51 \\
1.50 \\
3.36\end{array}$ & $\begin{array}{l}\text { ICRP-26 } \\
\text { ICRP-26 } \\
\text { ICRP-26 }\end{array}$ \\
\hline (TEPC/Model) & 1.26 & 1.12 & 0.89 & ICRP-26 \\
\hline \multicolumn{5}{|c|}{ STS-51 $\left(28.5^{\circ} \times 290 \mathrm{~km}\right)$} \\
\hline Payload (TEPC) & 43.5 & 144.2 & 3.31 & ICRP-60 \\
\hline $\begin{array}{l}\text { GCR Model } \\
\text { Albedo } \\
\text { Total (Model) }\end{array}$ & $\begin{array}{l}34.5 \\
14.0 \\
48.5\end{array}$ & $\begin{array}{r}120.0 \\
34.0 \\
154.0\end{array}$ & $\begin{array}{l}3.48 \\
2.43 \\
3.18\end{array}$ & $\begin{array}{l}\text { ICRP-60 } \\
\text { ICRP-60 } \\
\text { ICRP-60 }\end{array}$ \\
\hline (TEPC/Model) & 0.90 & 0.94 & 1.04 & ICRP-60 \\
\hline
\end{tabular}

The agreement found in Figure 1 requires clarification of the relationship between calculations and detector response, especially for high energy ions. Three basic assumptions are required in order for a direct comparison of lineal energy spectra to LET spectra to be meaningful. The ion trackwidth must be small compared to the gas volume dimensions, the LET across the volume must be constant, and nuclear fragments produced in the gas must be in equilibrium with the wall source terms. Trackwidth effects for ions passing through the gas lose energy to the wall thus reducing the energy deposit and effectively shifting to lower lineal energy values. HZE ions passing through the wall leak electrons into the gas volume forming energy pulses at relatively low lineal energies. 
Low energy ion fragments produced in the wall material tend to stop in the gas and register as relatively low lineal energy events. For example, in $2 \mu \mathrm{m}$ device the LET $=100 \mathrm{keV} / \mu \mathrm{m}$ protons are registered in the $y \approx 10 \mathrm{keV} / \mu \mathrm{m}$ region. The spectra of larger fragments are similarly distorted at higher $y$ values. Because of the finite size of the active volume of the dosimeter, fragments produced within the gas are similarly distorted.

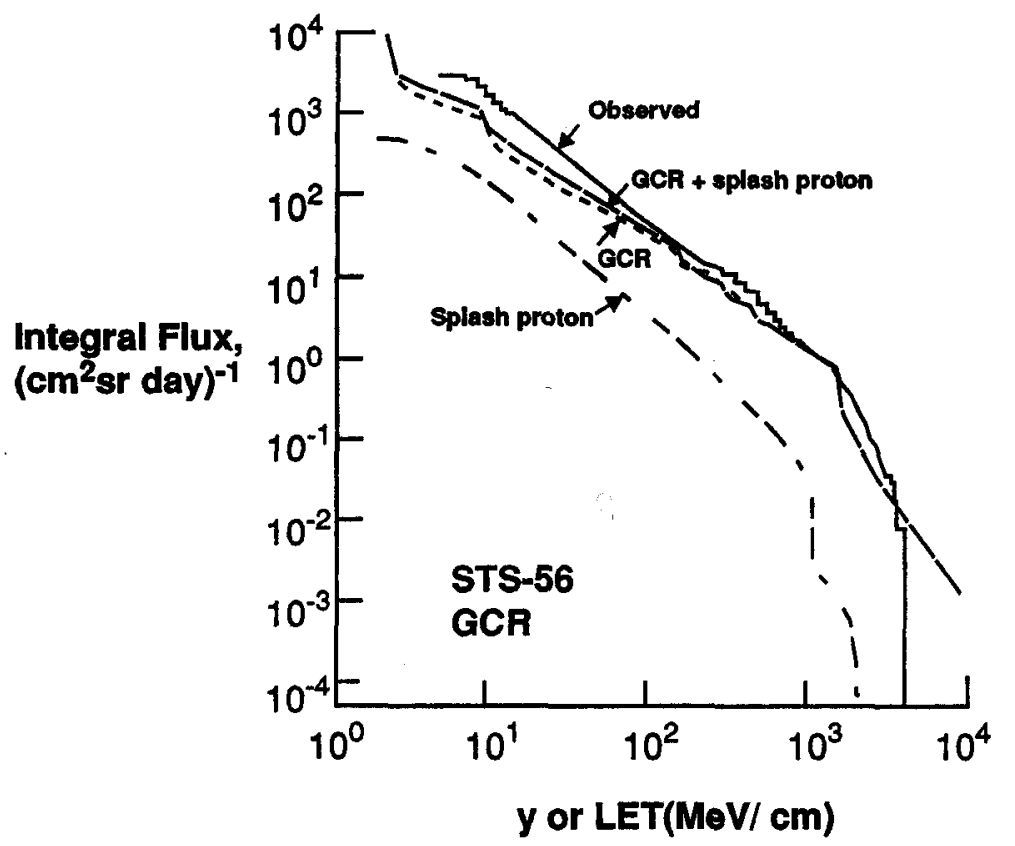

Fig. 1. Comparisons of calculations to measurements for lineal energy transfer $(y)$ spectra or linear energy transfer (LET) spectra from GCR on STS-56.

\section{TRACK STRUCTURE MODEL}

Characterization of the physical environment is necessary to evaluate biological risk factors. Biological risk models must be capable of representing the complex nature of the mixed radiation fields. The cellular track model of Katz et al. /12/ is able to represent important track structure effects by attributing biological damage from energetic ions to secondary electrons (delta rays) produced along the ion's path. The effects caused by energetic ions are correlated with those of gamma rays by assuming that sensitive sites near the ion's path are part of a larger system irradiated with gamma rays at the same dose, and are then studied through the radial dose distribution. The response due to ion effects is then determined by knowledge of the gamma ray response and the delta ray dose surrounding the ion's path.

There is no restriction on the dose response model for gamma-rays to be used when applying the concepts of Katz for studying heavy ion effects. In the past, calculations have been made with either an exponential response model (one-hit or one-target inactivation) or a multi-target or multi-hit model. For a multi-target model with target number $m$, the inactivation of cells is assumed to follow a distribution reflecting the random accumulation of sublethal damage with a radio sensitivity parameter $E_{0}$ as given by

$$
P(D)=\left(1-e^{-D / E_{0}}\right)^{m}
$$

The target number refers to the number of sensitive sites which must be damaged for the response to occur. For a multi-hit model with $c$ hits required to cause inactivation the inactivation probability is given by a Poisson distribution as

$$
P(D)=\left[1+(c !)^{1 / c} \frac{D}{E_{0}}+\cdots \frac{(c !)^{(c-1) / c}}{(c-1) !}\left(\frac{D}{E_{0}}\right)^{(c-1) / c}\right] e^{-(c !)^{1 / c}\left(D / E_{0}\right)}
$$


Wilson et. al. /14/ have considered a linear kinetics model for inactivation in the context of the Katz model for track structure. In this model enzymatic repair is expected to be less efficient with increasing number of hits with complete saturation of repair capability occurring for $c$ or more hits. For a cell receiving fewer than $c$ hits misrepair may occur with a branching ratio $\alpha_{m} / \alpha$ with the corresponding repair branching ratio given by $\left(1-\alpha_{m} / \alpha\right)$ and the gamma-ray response function is

$$
P(D)=\left[1+\frac{\alpha_{r_{1}}}{\alpha_{1}}(c !)^{1 / c} \frac{D}{E_{0}}+\cdots \frac{\alpha_{r_{c-1}}}{\alpha_{c-1}} \frac{(c !)^{(c-1) / c}}{(c-1) !}\left(\frac{D}{E_{0}}\right)^{c-1}\right] e^{-(c l)^{1 / c} \frac{D}{E_{0}}}
$$

where $\alpha_{r}=\alpha-\alpha_{m}$ and the $\alpha$ integer subscripts refer to number of hits. Equation (4) reduces to equation (3) in the limit of $\alpha_{m} / \alpha \rightarrow 0$. Other than the introduction of the repair/misrepair model /15/ for the gamma-ray response function the track structure dependent kinetics model /15/ follows the ideas of Katz and is described next.

For the inactivation by ions, two modes are identified when $m$ or $c>1$ : "ion kill" which corresponds to intratrack effects and "gamma-kill" which corresponds to intertrack effects. Here the ion-kill mode describes the single particle inactivation with cross section $\sigma$. The inactivation cross section for a sensitive site is:

$$
\sigma=\int_{0}^{\infty} 2 \pi t d t P[\bar{D}(t)]
$$

where $\bar{D}$ is the average dose at the sensitive site at radial distance $t$ from the ion's delta rays. In equation (5) the function $P$ is the gamma-ray response function from equation (2), (3), or (4) with the gamma-ray dose replaced by the ion's averaged radial dose. The description of cell damage is separated by Katz et al. /12/ into a so-called grain count regime, where inactivation occurs randomly along the path of the particle, and into the so-called track width regime, where many inactivations occur to sensitive targets not intersected by the particle's path, and are said to be distributed like a 'hairy rope'.

The fraction of cells damaged in the ion-kill mode is $P=\sigma / \sigma_{0}$. The track model assumes that a fraction of the ion's dose $(1-P)$ acts cumulatively with the action of other particles in the gamma-kill mode. The surviving fraction of an initial population $N_{0}$ whose response parameters are $m$ or $c, E_{0}$, and $a_{0}$ after irradiation by a fluence of particles $F$ is then written /12/:

$$
\frac{N}{N_{0}}=\Pi_{i} \times \Pi_{\gamma}
$$

where

$$
\Pi_{i}=e^{-\sigma F}
$$

is the ion-kill probability and

$$
\Pi_{\gamma}=1-P\left(D_{\gamma}\right)
$$

is the gamma-kill probability. The gamma-kill dose fraction is

$$
D_{\gamma}=(1-P) D
$$

where $D$ is the absorbed dose. Note that in the track width regime $\sigma>\sigma_{0}$ and it is assumed that $\Pi_{\gamma}=1$.

The radial dose model used in calculations is basically the model of Koebetich and Katz /16/ using recent models for secondary electron production and the electron range-energy formula and stopping power. In this model the radial dose $D(t)$ as a function of the radial distance $t$ from the 
center of the ion's path and including an angular distribution for the ejected electrons with energy $W$ at an angle $\theta$ is given by

$$
D(t)=\frac{-1}{2 \pi t} \sum_{i} \int d \Omega \int_{\omega_{t}(\theta)}^{\omega_{m}-I_{i}} d \omega \frac{\partial}{\partial t}[\eta(t, \omega, \theta) W(t, \omega, \theta)] \frac{d n_{i}}{d \omega d \Omega}
$$

where $\omega_{m}$ is the maximum secondary electron energy, $I_{i}$ is the ionization energy for an electron, $\eta$ is the transmission function, and $W$ is the residual energy of the electrons. In equation (10) the summation is over all atoms. The range-energy formula assumed are from Tabata, et al. $/ 18 /$ and the transmission functions from Kobetich and Katz /19/.

A qualitative model for the angular distribution of the secondary electrons is to assume a distribution peaked about the classical ejection value, such as $/ 20 /$

$$
\frac{d n}{d \omega d \Omega}=\frac{d n}{d \omega} f(\theta, \omega)
$$

where

$$
f(\theta, \omega)=\frac{N}{\left[\theta-\theta_{c}(\omega)\right]^{2}+\frac{A}{\omega}}
$$

with $\theta_{c}(w)$ determined as the root of

$$
\cos ^{2} \theta=\frac{\omega}{\omega_{m}}
$$

and $N$ a normalization constant, and $A$ a constant found to be about $0.015 \mathrm{keV}$ to simulate the data of $/ 21,22 /$. For the single differential distribution in equation (11) we use the model of Rudd /17/ scaling to heavy ions using effective charge. Extensive comparisons of the model described above to experiments for radial dose from heavy ions are described in $/ 20 /$. The use of the model of Rudd and the angular distribution of equations (11)-(13) generally reduces the dose in the core region relative to a normal ejection model and the Rutherford formula.

\section{GROUND-BASED MEASUREMENTS FOR SPORE INACTIVATION}

The inactivation of $B$. Subtilis spores has been measured in a variety of experiments with a large number of radiation types /23-25/. The response of spores are known to vary with their strain. Baltschukat and Horneck /24/ have provided X-ray response parameters for strains denoted wild-type, indicating the characteristics of DNA repair capability, and pol- which carries a repair defect in DNA polymerase I. Survival data have been represented by the function /24/

$$
\ln \left(N / N_{0}\right)=-D / E_{0}+m
$$

Parameter values ( $m$ and $E_{0}$ ) are listed in Table 2. Both models provide good fits over the dose-range measured in the experiments. A small shoulder occurs in the X-ray survival curves. In the kinetics model the differences between the two strains is explained by varying the repair capacity with $E_{0}$ held constant. A third strain of spores indicates a pure exponential response to X-rays with $E_{0}=93 \pm 6 \mathrm{~Gy} / 24 /$.

Survival curves following heavy ion bombardment show exponential response and an inactivation cross section was extracted from the experiments /24/. Representation of these data in the Katz model requires fitting the size parameters $a_{0}$ and $\sigma_{0}$ which are listed in Table 2 for the wild-type spores. Comparisons to the experiment for inactivation cross sections are shown in Figure 2 versus the ion LET. The data for $\mathrm{H}$ and He bombardment are from /23/ (assumed to be of the wild type) and data for heavier ions from /24/. The solid lines in Figure 2 are the final slope cross sections from the Katz model /12/ and dashed lines the initial slope cross sections for $\mathrm{H}$ and He. For heavy ions the model initial and final slope cross sections are identical or nearly identical 
TABLE 2 Response parameters for inactivation of $B$. Subtilis spores

\begin{tabular}{|c|c|c|c|c|c|c|}
\hline & \multicolumn{6}{|c|}{ Strain } \\
\hline & \multicolumn{3}{|c|}{ Wild } & \multicolumn{3}{|c|}{$\mathrm{Pol}^{-}$} \\
\hline & Expt. & Katz & Kinetics & Expt. & Katz & Kinetics \\
\hline $\mathbf{m}$ & 2 & 2 & 2 & 1.4 & 1.4 & 2 \\
\hline$E_{0}, G y$ & $222 \pm 18$ & 222 & 240 & $170 \pm 11$ & 170 & 240 \\
\hline$\alpha_{m} / \alpha$ & - & - & 0.1 & - & - & 0.9 \\
\hline$a_{0}, \mu m$ & - & .13 & .13 & - & .13 & .13 \\
\hline$\sigma_{0}, \mu m^{2}$ & - & .15 & .15 & - & .15 & .15 \\
\hline
\end{tabular}

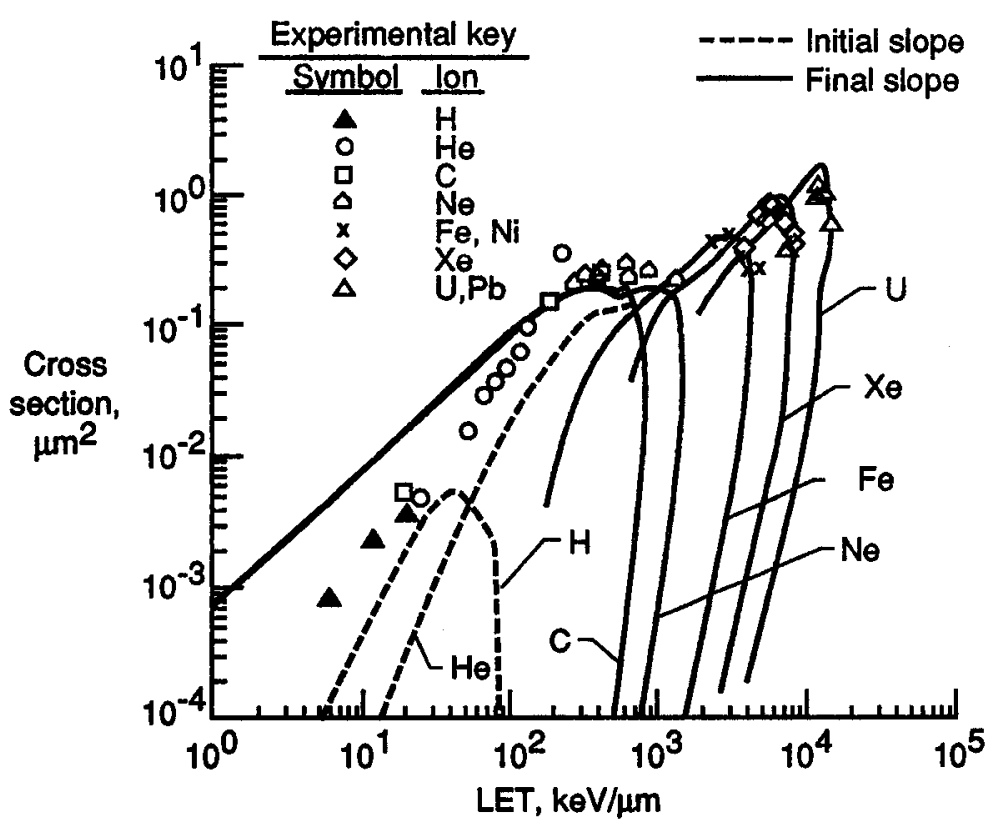

Fig. 2. Comparison of measured inactivation cross sections versus LET /24/ to calculations in Katz model. Solid line is final slope of model and dash line is initial slope of model.

in all cases. In Figure 3 the initial slopes in the kinetic model is compared to the experiment. Note that there is a changing slope for low LET ions with increasing dose in a multi-hit model, while the multi-target model becomes pure exponential at large dose. The agreement with experiment is good. The low velocity cross section below the region of thindown from delta-ray effects is of interest. Here the kinetics model predicts a second maximum in the action cross section at the Bragg peak due to misrepair. The low velocity peak is expected to be larger for the $\mathrm{pol}^{-}$strain which are repair deficient.

Inactivation as a function of impact parameter has been measured for $1.4 \mathrm{MeV} / \mathrm{u}$ heavy ion beams $/ 25$ / using wild strain spores. In Figures $4 a$ and $4 b$ we compare to these measurements using the present model. In one set of calculations (the upper set of curves) we consider the measured impact parameter relative to the sensitive site in the spore. Here there is unit probability for inactivation following uranium bombardment out to about $0.2 \mu \mathrm{m}$ and for nickel bombardment to about $0.15 \mu \mathrm{m}$. Note that this is different from the calculations of $/ 25 /$ 


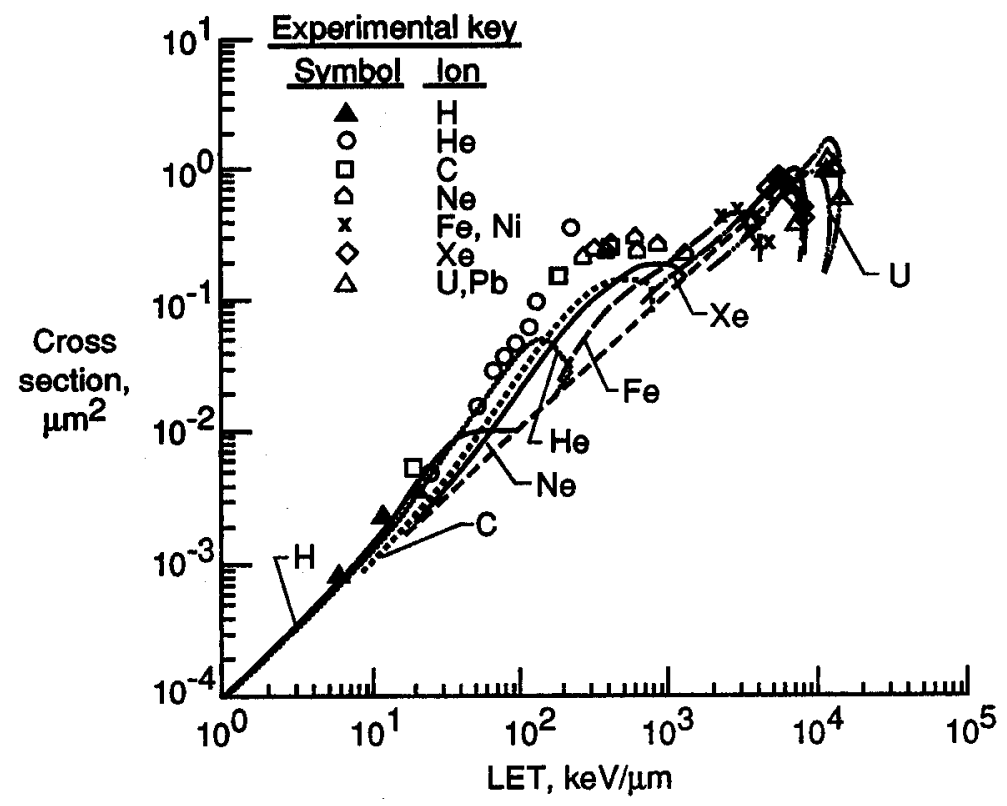

Fig. 3. Comparison of measured inactivation cross sections versus LET /24/ to calculations for initial slopes in kinetic model.

\subsection{MoV/amu U}

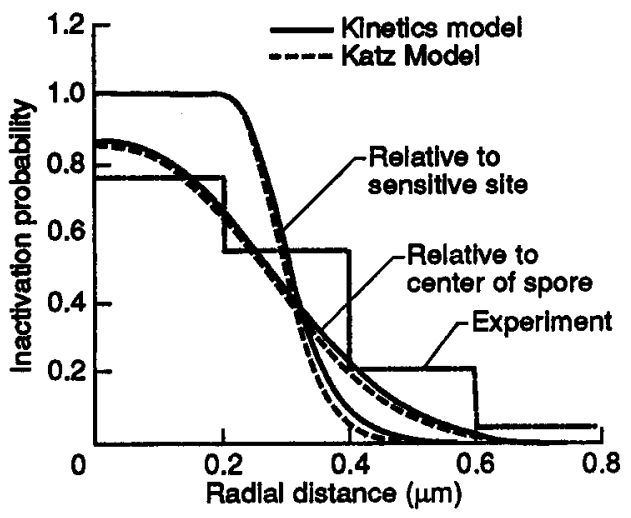

Fig. 4a. Calculations of inactivation as a function of impact parameter for $1.4 \mathrm{MeV} / \mu \mathrm{m}$ uranium ions and experimental values $/ 25 /$.

\subsection{MoV/amu NI}

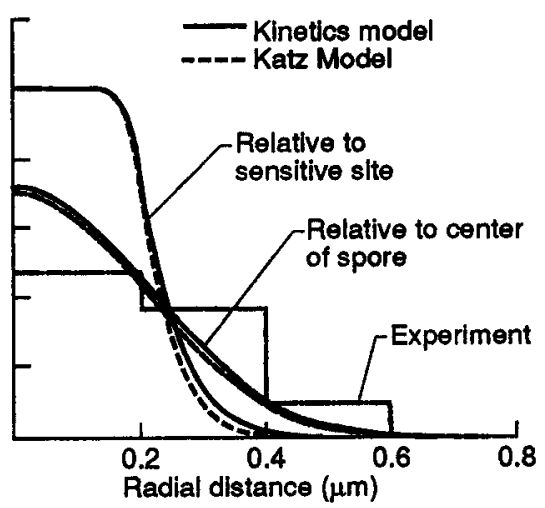

Fig. 4b. Calculations of inactivation as a function of impact parameter for $1.4 \mathrm{MeV} / \mu \mathrm{m}$ nickel ions and experimental values $/ 25 /$.

where a one-hit response is assumed and the radial dose model of Butts and Katz /26/ was used. Using this earlier version of the Katz model the inactivation probability for uranium was found to be unity for larger impact parameters, and the electron range is underestimated. The calculations described herein suggest that the use of more accurate radial dose models are important. In the lower set of curves we have used the estimates of the size of the spore in /25/ to average the inactivation probability according to a random location for the sensitive volume in the spores. Here we have averaged over two short cylinders of radius corresponding to the estimated minor $(.18 \mu \mathrm{m})$ and major $(.36 \mu \mathrm{m})$ radii of an ellipsoid shaped spore. The lower set of curves is in much better agreement with the experiment and it is expected that details of the geometry of the spores and the sensitive sites are required for further improvements of calculations to experiment. 


\section{FLIGHT MEASUREMENTS FOR SPORE INACTIVATION}

The Biostack measurements of spore inactivation in spaceflight on the Apollo-Soyuz Test Project (ASTP) were designed to measure the response of the spores to single HZE particles /9,11/. Several strains of spores including wild and pol- $^{-}$were used $/ 11 /$. The experimental design held the spores in fixed contact with a plastic detector sheet (cellulose nitrate (CN)). Track etching techniques allowed the inactivation probability as a function of impact parameter to be determined to an accuracy of $0.2 \mu \mathrm{m}$. These measurements indicated that spores were inactivated up to impact parameters of $4 \mu \mathrm{m}$, beyond the range expected from ground-based measurements $(<1 \mu \mathrm{m})$. The estimated inactivation cross largely exceeds that seen in ground-based measurements with heavy ions $/ 9,11 /$.

The CN detector sheet has a threshold for particle identification which allows for only highly ionizing particles to be detected. Cosmic-ray ions below the CN sensitivity threshold would register as a background to the inactivation probability. Horneck /9/ identifies the range of ions with $\mathrm{Z} \geq 12$ and LET $\geq 200 \mathrm{keV} / \mu \mathrm{m}$ as being inactivated with significant numbers to be investigated. Details on the evaluation of the Biostack experiments on ASTP are described in /27/. Katz and Kobetich $/ 28$ / have studied CN response and found the radial dose at about $20 \AA$ from an ion's passage to be the important parameter in determining the CN's threshold for particle identification. The orbital parameters for ASTP were an inclination of $51.6 \mathrm{deg}$ and altitude of $121.5 \mathrm{NM}$ for 9 days. The spacecraft shielding was about $2.4 \mathrm{~g} / \mathrm{cm}^{2}$ of aluminum. We have calculated the total inactivation probability for this mission from the GCR using HZETRN and the track structure model with results shown in Table 3. Also shown in Table 3 are predictions for several other endpoints in mammalian cell lines. The background to the spore inactivation for the total GCR spectrum is extremely small. Estimates for the exposure to trapped protons on ASTP were significantly less than the GCR.

TABLE 3 Biological damage probabilities for $51^{\circ} \times 121.5 \mathrm{NM}$ Orbit from GCR at $2.5 \mathrm{~g} / \mathrm{cm}^{2}$ Aluminum shielding for 9 days

\begin{tabular}{|l|l|}
\hline \multicolumn{1}{|c|}{ Endpoint } & Probability \\
\hline B. Spore Inactivation & $0.5 \times 10^{-4}$ \\
C3H10T1/2 Inactivation & $2.2 \times 10^{-4}$ \\
C3H10T1/2 Transformation & $0.7 \times 10^{-7}$ \\
\hline
\end{tabular}

In order to compare to the Biostack measurement we have made calculations with Fe particle in the stopping region which are the most likely ions to be seen above the CN threshold. In Figure 5 we show calculation for $15 \mathrm{MeV} / \mathrm{amu} \mathrm{Fe}$ ions in comparison to the measurements $/ 9,11 /$. The control value for spore inactivation is given as $12( \pm 3)$ percent and we have subtracted 12 percent from the measurement in Figure 5. In Figure 5 calculations were made using the experimentally determined response parameters following X-ray irradiation for 3 strains of spores with different repair capacities /24/. The repair deficient $\mathrm{rec}^{-}$strain is seen to provide the largest inactivation probability at large impact parameters, however not sufficient to explain the measurements at the largest distances. The increase in inactivation probability for the repair deficient strains is consistent with ground-based results for the inactivation cross section with high LET ions /24/. Fritz-Niggli /28/ has discussed the possibility of microgravity altering the repair capacity of DNA. The calculations presented here suggest that a further decrease in repair capacity from the rec spore strain could explain the results seen in Biostack. 


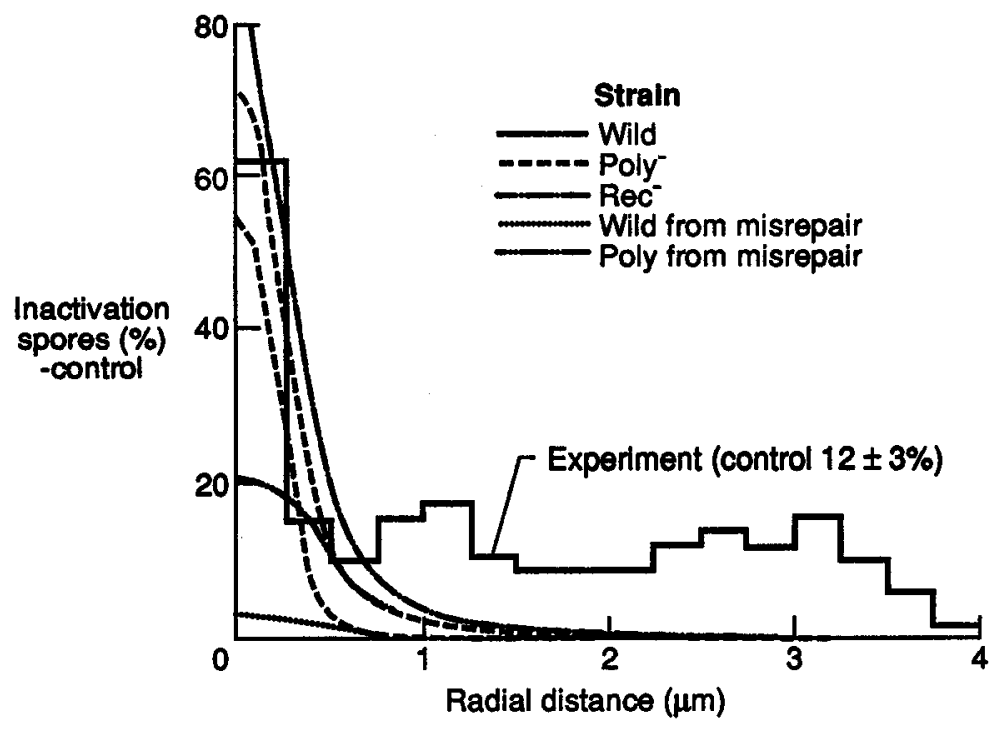

Fig. 5. Inactivation as a function of impact parameter as measured by Biostack $/ 9,11 /$ and calculations for $15 \mathrm{MeV} / \mathrm{amu}$ Fe for the response of three different spore strains.

\section{CONCLUDING REMARKS}

State-of-the-art cosmic ray transport codes are able to predict the absorbed dose and dose equivalent to an accuracy of about 30 percent. The accuracy of predictions of particle spectra such as the lineal energy or linear energy transfer spectra awaits further clarification of the relationship between detector response and the energy spectrum evaluated by transport codes. Even with improvements in these areas, the expectation that the dose equivalent determines the expected risk in space should be challenged. The anomaly seen by the Biostack experiment for the endpoint of inactivation of bacteria awaits further spaceflight experiments for clarification of the results. However, these results suggest that further understanding of the track structure of heavy ions and of biophysical response models are needed for validation of risk assessment methods for space radiations.

\section{REFERENCES}

1. W. S. Schimmerling, Radiobiological Problems in Space: An Overview, Radiat. Environ. Biophys., 31, 197 (1992).

2. J. W. Wilson, L. W. Townsend, W. Schimmerling, G. S. Khandelwal, F. Khan, J. E. Nealy, F. A. Cucinotta, L. C. Simonsen, J. L. Shinn, and J. W. Norbury, Transport Methods and Interactions for Space Radiations, RP 1257, NASA, Washington, DC (1991).

3. F. A. Cucinotta, Calculations of Cosmic Ray Helium Transport in Shielding Materials, TP 3354, NASA, Washington, DC (1993).

4. J. L. Shinn, S. John, R. K. Tripathi, J. W. Wilson, L. W. Townsend, and J. W. Norbury, Fully Energy Dependent HZETRN (A Galactic Cosmic-Ray Transport Code), TP-3242, NASA, Washington, DC (1993).

5. G. D. Badhwar and P. M. O'Neill, An Improved Model of GCR for Space Exploration Missions, Nucl. Tracks Radiat. Meas., 20, 403 (1992).

6. J. H. Adams, Jr., R. Siberberg, and C. H. Tsao, Cosmic Ray Effects on Micro-electronics, Part IV, Naval Research Laboratory Memorandum Report 5901 (1986).

7. G. D. Badhwar, F. A. Cucinotta, L. A. Braby, and A. Konradi, Measurements on the Shuttle of the LET Spectra of Galactic Cosmic-Rays and Comparisons with Radiation Transport Model, Radiat. Res., 139, 344 (1994). 
8. J. F. Dicello, M. Wasiolek, and M. Zaider, Measured Microdosimeter Spectra of Energetic Ion Beams of Fe, Ar, Ne, and C: Limitations of LET Distributions and Quality Factors in Space Research and Radiation Effects, IEEE Trans. Nucl. Sci., 38, 1203 (1991).

9. G. Horneck, Radiobiological Experiments in Space: A Review, Nucl. Tracks Radiat. Meas., 20, 185 (1992).

10. G. A. Nelson, W. W. Schubert, and T. M. Marshall, Radiobiological Experiments with Caenorhabditis Elegans. Genetic and Developmental effects of High LET Radiations, Nucl. Tracks Radiat. Meas., 20, 227 (1992).

11. G. Horneck, M. Schafer, K. Baltshukat, Y. Weisbrod, U. Micke, R. Facius, and H. Bücker, Cell Inactivation, Repair and Mutation Induction in Bacteria After Heavy Ion Exposure: Results From Experiments at Accelerators and in Space, Adv. Space, Res., 9, 105 (1989).

12. R. Katz, B. Ackerson, M. Homayoonfar, and S. C. Sharma, Inactivation of Cells by Heavy Ion Bombardment, Radiat. Res., 47, 402 (1971).

13. J. W. Wilson, Analysis of the Theory of High-Energy Ion Transport, NASA TND-8381 (1977).

14. T. W. Armstrong and B. L. Colburn, Predictions of Induced Radioactivity in LEO, Nucl. Tracks Radiat. Meas., 20, 101 (1992).

15. J. W. Wilson, F. A. Cucinotta, and J. L. Shinn, Cell Kinetics and Track Structure, in: Biological Effects and Physics of Solar and Galactic Cosmic Radiation, eds. C. E. Swenberg, G. Horneck, and E. G. Stassinopoulos, Plenum Press, 1993, p. 295.

16. E. J. Kobetich and R. Katz, Energy Deposition by Electron Beams and $\delta$-rays, Phys. Rev., 170,391 (1968).

17. M. E. Rudd, User-Friendly Model for the Energy Distribution of Electrons From Proton or Electron Collisions, Nucl. Tracks Radiat. Meas., 16, 213 (1989).

18. T. Tabata, R. Ito, and S. Okabe, Generalized Semi-Empirical Equations for the Extrapolated Range of Electrons, Nucl. Instrum. and Meth., 103, 85 (1992).

19. E. J. Kobetich and R. Katz, Electron Energy Dissipation, Nucl. Instrum. and Meth., 71, 226 (1969).

20. F. A. Cucinotta, R. Katz, J. W. Wilson, and R. R. Dubey: Heavy Ion Truck Structure Calculations for Radial Dose in Arbitrary Media, NASA Technical Paper (in press) (1994).

21. M. E. Rudd, L. J. Toburen, and Stolterfoht, Differential Cross Sections for Ejection of Electrons From Helium by Protons, Atomic and Nuclear Data Tables, 18, 413 (1976).

22. L. H. Toburen, Distribution in Energy and Angle of Electrons Ejected From Xenon by 0.3 to $0.2 \mathrm{MeV}$ Protons, Phys. Rev., A9, 2505 (1974).

23. J. E. Donnellan, Jr. and H. J. Morowitz, The Irradiation of Dry Spores of Bacillus Subtilis with Fast Charged Particles, Radiat. Res., 7, 71 (1957).

24. K. Baltshukat and G. Horneck, Responses to Accelerated Heavy Ions of Spores of Bacillus Subtilis of Different Repair Capacity, Radiat. Environ. Biophys., 30, 87 (1991).

25. U. Weisbrod, H. Bücker, G. Horneck, and G. Kraft, Heavy Ion Effects on Bacteria Spores: The Impact Parameter Dependence of the Inactivation, Radiat. Res., 129, 250 (1993).

26. J. J. Butts and R. Katz, Theory of RBE for Heavy Ion Bombardment of Dry Enzymes and Viruses, Radiat. Res., 30, 855 (1967). 
27. R. Facius, H. Bücker, G. Horneck, G. Reitz, and M. Schäfer, Dosimetric and Biological Results from the Bacillus Subtilis Biostack Experiment with the Apollo-Soyuz Test Project, Life Sci. Space Res., 17, 123 (1979).

28. R. Katz and E. J. Kobetich, Formation of Etchable Tracks in Dielectrics, Phys. Rev., 170, 401 (1968).

29. H. Fritz-Niggli, Modifying Factors on Repair Phenomena, Adv. in Space Res., 9, 187 (1989). 